This is the 'accepted' version of:

Hussein, S., Manthorpe, J. and Ismail, M. (online, 2014) Male workers in the femaledominated long-term care sector: evidence from England. Journal of Gender

Studies. $6^{\text {th }}$ March 2014, doi: 10.1080/09589236.2014.887001

\title{
Male workers in the female-dominated long-term care sector: evidence from England
}

\author{
Shereen Hussein ${ }^{\mathrm{a}^{*}}$, Mohamed Ismail ${ }^{\mathrm{b}}$ and Jill Manthorpe ${ }^{\mathrm{a}}$ \\ aSocial Care Workforce Research Unit, King's College London, Strand, London WC2R 2LS, UK; \\ ${ }^{\mathrm{b}}$ Analytical Research Ltd, Station House, Connaught Road, Surrey GU24 0ER, UK
}

\begin{abstract}
Labor market changes, including growing opportunities to work in the long term care (LTC) sector, may attract more men to this traditionally female-dominated occupation. Analyzing an English national workforce data set we investigate whether men are remaining within traditional masculine jobs or crossing traditional boundaries into more emotional, and personal care work. We examine organization, local area effect and service provision on the probability of attracting more men to the workforce. The analysis utilizes multivariate statistics and mixed-effect models. The findings highlight both horizontal and vertical segregation in the types of jobs undertaken by men in LTC. A research agenda is identified.
\end{abstract}

Keywords: masculinity and care; labor participation; emotional work

\section{Background}

Long term care (LTC), or social care, is defined as work that supports older people, or adults with long term illness or disabilities, with activities of daily living and personal care. Globally paid LTC work is a female dominated occupation; with women forming up to 95 percent of the workforce in some European countries (Geerts, 2011). Explanations for the concentration of women working in the LTC sector suggest that this is a product of interacting societal, occupational and gender phenomena. Gender is conveyed through structures of power and authority with men tending to be concentrated in positions of power, even within occupations that are femaledominated such as LTC work (Cross and Bagihole, 2002; McLean, 2003). Caring for older people and people with disabilities has traditionally and continues to be conceptualized as female work, or as requiring female skills in most countries (Lynch, 2007). However, the same ascribed and perceived feminine nature of care work itself is sometimes theorized as being associated with the assigned value of care jobs as reflected in the limitations of its pay, career opportunities and general working conditions (England, Allison \& Wu, 2007; Alksnis, Desmarais \& Curtis, 2008). This is despite the fact that LTC work is 'expensive' both at individual and societal levels. Yet, as Cameron and Moss (1998) indicated, 'caring work is gendered not just because the workforce is nearly always women but because of the way the work is thought about'. 
While it is not straight forward to classify an occupation as masculine or feminine in nature, society ascribes certain characteristics to some occupations. For example, human services work, including care work, has long been characterized as feminine (Twigg, 2000), acknowledging that such categorization may be challenged by individuals and sometimes organisations. Considerable and increasing numbers of men and women have been moving into gender atypical job roles(Hakim, 1996). While some women may pursue traditionally male careers for the power and authority they usually yield, such as prestige, higher pay and opportunities, or purely as a demonstration of equality, little is known about men who enter traditionally female occupations (for exceptions in the profession of social work see Christie 1998; Pease 2011). Recent research has started to pay more attention to understanding male motivations and career choices in other non-traditional jobs, for example as nurses (Simpson, 2004; McMillian, Morgan \& Ament, 2006; Loughrey, 2008). Some research has sought to conceptualize why some men cross boundaries to join femaledominated occupations; in relation to individual characteristics including links to social class (Lupton, 2006), migration status (Datta et al, 2009) and labor market processes (Williams \& Villemez, 1993). However, theoretical understandings of the experiences of men are still in their infancy and fragmentary.

A combination of individual with societal and global factors appears to affect men's attitude to careers, decisions and choices about labor market participation. Ageing, population change, globalization and labor market dynamics are long-standing trends that may directly influence both men and women's occupational choices in developed countries. For example, much of the growth of the LTC sector is attributed to population ageing and changes in family structures. Such social changes enhance opportunities for female-dominated jobs, with over three million related jobs created between 2000 and 2007 in the European Union alone (Bettio \& Vershchagina, 2008). The LTC sector is likely to become even more important in attracting new recruits during times of economic hardship, rising unemployment and current reductions in public spending in societies such as the United Kingdom (UK). During the past couple of decades there is some evidence that such structural changes, such as service privatization, increased use of personal budgets and cultural shifts towards providing LTC in people's own homes, have been providing new employment opportunities for some groups of men as well as women, for example, migrant men (Solari, 2006; Solano \& Rafferty, 2006). In addition, there is evidence that gender role segregation in human services employment is becoming increasingly blurred. Labor market changes, role models and career ambitions are some of the interacting factors that shape employment choices and actions. In the human services workforce career patterns between genders may differ, for example, in the United States (US), Jacobs (1993) found that men entering female-dominated jobs had higher occupational mobility and tended to move rapidly into and out of such jobs. A later UK study of men working in female-dominated occupations indicated that some men, especially those with relevant skills, experience high job satisfaction and are less likely to perceive their jobs as 'women's work' (Bagilhole \& Cross, 2006); perhaps reflecting Hakim's (1996) argument about the importance of men and women's individual rather than structural preferences.

In the UK, which experiences continual workforce shortages in the LTC sector, there is growing interest in how to attract non-traditional workers; including men and younger people (Barnard and Statham, 2012). This 'interest' occurs largely in 
isolation from efforts seeking much needed substantial improvements in pay and working conditions in the sector for both men and women. A recent study (Vector Research, 2009) considering ways of improving the recruitment of men into the LTC sector found that men's individual perceptions, life-course stage and their access to care jobs appear to shape men's deliberations. In addition to individual perceptions, the researchers concluded that perceptions of difficult work conditions, and structure, tend to make men reluctant to join the sector.

Despite these perceptions, the LTC sector incorporates a broad range of roles and activities, those involving hands-on-care and others not, such as technical and ancillary roles. Some of these roles may be considered more 'masculine' than others, such as management and technical jobs, thus it is likely that when men are attracted to the sector that they concentrate in such jobs. Particular men, such as migrants, may be more willing to accept gender atypical jobs in order to facilitate their entry to the UK or as a stepping-stone into the wider British labor market (Hussein, Manthorpe \& Stevens, 2011; Hussein, 2011a). In addition to personal factors, organizational factors may have a role in attracting and retaining men. Earlier research on men in the care sector found that they were more likely to perform managerial roles concluding that this was a reflection of authority and control, or that men concentrate in traditionally male roles, such as transport drivers (Davey, 2002; McLean, 2003).

A growing literature suggests certain career advantages for men who perceived feminine occupations, with concepts such as the 'glass escalator' as introduced by Williams (1992), being confirmed in some sectors such as nursing (Evans, 1997). However, more recent research has criticized this concept as it implies general advantages to 'all' men without considering the dynamics of race and migration (Hussein \& Christensen, forthcoming; Wingfield, 2009).

With the exception of a small amount of research, there is almost no equivalent body of literature on men working in LTC. Which men are attracted to the sector? What type of jobs do they hold? Are they more likely to be found in managerial or physically demanding care work than possibly more 'feminine' types of role? Do organizational characteristics play any role in recruiting men to the sector? This study aimed to investigate some of these research questions.

\section{Methods}

In 2011, an estimated 49,700 organizations or employers (hereafter referred to as establishments) were involved in providing LTC in England and were legally registered for this purpose. Nearly three-quarters of these establishments were in the independent sector (private for-profit or voluntary not for profit) with the rest being local authority run services (see Skills for Care [SfC], 2012). In response to a perceived need to know more about the sector's workforce, the government funded sector skills organization, Skills for Care, developed a National Minimum Data Set for Social Care (NMDS-SC) ${ }^{\mathrm{i}}$ to collect information from employers providing care services and their workforce. The current analysis utilizes NMDS-SC, end of March 2011, individual workers files, which contain detailed anonymized data on 642,777 workers' records in the social care sector in England. For each record, the employer provides considerable amounts of personal and workforce information ${ }^{\text {ii }}$. Personal information includes date of birth, sex, and reported disability and, for a large sample, nationality and country of birth. Of the 642,777 workers' records reported in NMDS- 
SC March 2011, a relatively small number of records $(43,755)$ did not include any information on gender and were subsequently excluded from the analysis reported here (total valid sample 599,022).

The aim of our analysis is to answer three main research questions: 1) What is the profile of men working in the English LTC sector; 2) what are the relationships between personal profile and job roles; and 3) What are the characteristics of organizations that appear to be more successful in attracting men compared to others (including the type of client or end user group). These research questions have not been examined before in relation to LTC and contribute to the debate around certain conceptual ideas, such as the 'glass escalator' if men are more prevalent in managerial and 'authoritative' job roles (Williams, 1992); the ethnic and migration dynamics when different groups of men join 'feminine' occupation with possible evidence of 'glass barriers' being encountered by certain groups (Wingfield, 2009; Kilkey, 2010); and how some may retain 'masculine' identities by choosing gender acceptable masculine roles, such as technical jobs, within the feminine occupation of LTC (Lupton, 2000).

We have used the NMDS-SC to investigate our main three questions using different statistical techniques including mixed-effect models, implemented on $\mathrm{R}$ statistical environment on UNIX. We further linked NMDS-SC to local area Multiple Deprivation Index (MDI 2007) and Office for National Statistics (ONS) area urban/rural classifications ${ }^{\mathrm{iii}}$ to examine local area effect on the prevalence of male workers in different organizations.We employed forward step-wise mixed-effect models introducing different characteristics and interactions ${ }^{\mathrm{iv}}$.

\section{Findings}

\section{The profile of men working in long term care (LTC)}

Overall, 17.1 per cent $(n=102,694)$ of the national sample identified by employers as male. Men working in the sector, as reported in the NMDS-SC March 2011, were slightly younger than women with a mean age of 41.9 years, compared to 42.3 years for women $(\mathrm{F}=79.2, p<0.001)$ (see Table 1). Men's age was more evenly distributed around the ages of 30 to 50, unlike women whose age distribution peaked around 50 years. Significantly more men were reported by their employers to have some form of disability when compared to women $\left(3.3 \%\right.$ vs. $\left.1.9 \% ; \chi^{2}=740.5 ; \mathrm{df}=1 \mathrm{p}<0.001\right)$. This may relate to different disclosure patterns between men and women or occupational 'decline' with ill-health or disability; but it may also relate to job confidence, empowerment and the specific disability (Ellison, Russinova, MacDonald-Wilson \& Lyass, 2003). The data also indicated some difference in ethnicity by gender, with significantly more men identified by employers as belonging to a black or minority ethnic (BME) group ( $26 \%$ vs. $\left.17 \% ; \chi^{2}=4408.1 ; p<0.001\right)$. Ethnicity-gender difference was particularly evident in relation to workers identified as Asian or Asian British (9.1\% of men vs. $4.8 \%$ of women). Breaking this down, proportionally more men working in LTC were of Indian (3.9\%) or other Asian background (2.9\%) than women ( $1.9 \%$ and $1.6 \%$ respectively).

Employers completing the NMDS-SC returns are asked to list all qualifications held by their staff, from these Skills for Care derived a variable of 'highest qualification 
level' of individual workers. Overall the qualifications held by men and women working in LTC were similar, particularly that the majority of both groups held qualifications NVQ (National Vocational Qualification; currently under the Qualification Credit Framework) at level 3 or below. One difference was that men were more likely to hold other relevant qualifications, or no relevant qualifications, while women tended to have level 2 qualifications $\left(\chi^{2}=2164.3 ; p<0.001\right)$. The analysis also indicated that a slightly smaller percentage of men had completed their induction (initial training for a job) compared to women (67\% vs. $70 \%$ ).

Table 1 Distribution of men and women in the care sector by personal characteristics, NMDS-SC March 2011

\begin{tabular}{lcc}
\hline Personal characteristics & Men & Women \\
\hline Age (mean) & 41.9 & 42.3 \\
S.D. & 13.3 & 13.1 \\
Number of Cases $\dagger$ & 99541 & 481445 \\
\hline Reported Disability (\%) & 3.3 & 1.86 \\
Number of Cases & 88814 & 428841 \\
\hline Ethnicity & & \\
\hline White & $73.70 \%$ & $82.80 \%$ \\
Mixed & $1.90 \%$ & $1.50 \%$ \\
Asian or Asian British & $9.10 \%$ & $4.80 \%$ \\
Black or Black British & $10.90 \%$ & $7.70 \%$ \\
Other groups & $4.40 \%$ & $3.10 \%$ \\
\hline Number of Cases & 86,599 & 423,200 \\
\hline Entry/Level1 & $1.50 \%$ & $1.20 \%$ \\
Level 2 & $31.50 \%$ & $40.90 \%$ \\
Level 3 & $24.40 \%$ & $27.10 \%$ \\
Level 4 & $15.20 \%$ & $11.20 \%$ \\
Other relevant qualifications & $22.80 \%$ & $17.00 \%$ \\
No relevant qualifications & $4.50 \%$ & $2.70 \%$ \\
\hline Number of Cases & 35,935 & 212,823 \\
\hline Nationality & \multicolumn{2}{|}{} \\
\hline Migrant & $20.90 \%$ & $13.10 \%$ \\
British & $79.10 \%$ & $86.90 \%$ \\
\hline Number of Cases & 73,316 & 352,825 \\
\hline$\dagger$ Number of cases may be different due to missing values &
\end{tabular}

From 2010, the NMDS-SC started collecting information on workers' nationality and country of birth from employers. The collection of these data items became part of employers' returns in October 2010. Employers are currently asked to indicate whether each individual worker is British or not; if identified as not British, employers are then asked to provide further information related to country of birth and year of entry to the UK. Up until June 2011, employers were not offered a 'don't know' field in relation to nationality, thus it is possible that employers who were 
unsure about some of their workers' nationalities may have indicated that they were British and consequently under-reported the contribution of migrants to the sectorv

Our analysis showed that more men working in the sector were identified as migrants (non British) than women (21\% vs. $13 \%)$. Among non-British workers, where employers provided information on their country of birth, the analysis showed that, similar to migrant women, migrant men in the sector were most often from The Philippines. Proportionally more migrant men were from India and Nigeria than women, while more migrant women were from Poland and Ireland.

\section{Job characteristics and gender}

The literature indicates that men who work in traditionally female roles may be attracted to certain job roles that confer power and authority such as management. Specific professions such as social work appeared to have attracted more men since it became a degree level qualification in England (GSCC, 2010), albeit there are less favorable progression rates among male students compared to females (Hussein, Moriarty \& Manthorpe, 2009; Furness, 2011). The current analysis shows that over half of men in LTC jobs worked as care workers (those providing hands on care in care home and home care or other settings) being the largest staff group in the sector for both men and women. The second largest group, which constituted 10 percent of men, consisted of ancillary staff (such as cooks, drivers and cleaners; compared to 7\% of women). Relatively more women were working in administrative roles (4\% vs. $2.9 \%$ ) and as registered nurses (4\% vs. $2.8 \%$ ) than men. On the other hand, relatively more men were working as senior managers $(1.8 \%$ vs. $0.8 \%)$; middle managers $(1.3 \%$ vs. $0.9 \%)$ and managers in care-related roles $(1.5 \%$ vs. $1 \%)$ than women. Almost equal proportions of men and women were employed as social workers ( $2 \%$ and $1.7 \%$ respectively). These differences were reflected more clearly when we examined the distribution of men and women by main job role groups ${ }^{\mathrm{vi}}$. The data showed that significantly more men held managerial/supervisory or other job roles than women (9.6\% vs. $7.7 \%$ and $18.8 \%$ vs. $13.2 \%$ respectively).

We also examined the prevalence of men within different job roles and how these compared to the average percentage of men in the overall LTC workforce as represented by the NMDS-SC. Figure 1 shows that the vast majority of technician jobs within the sector were performed by men (72\%); appearing to reflect the social acceptance of technical roles as masculine. That such jobs were performed within female dominated work settings did not seem to affect the gendered nature of such work. Other job roles where men were engaged more than women included employment support (37\%), youth offending support (36\%), senior management (32\%), counseling (28\%) and educational support (25\%). All of the latter jobs may perhaps be regarded as masculine or as 'gender neutral', particularly as they do not involve body work (Twigg, 2000).

While the analysis shows that men are over-represented in managerial and supervisory roles (10\% of men work in these jobs compared to $7 \%$ of women); men in managerial roles were almost entirely British rather than migrant men. Meanwhile the largest proportions of migrants (both male and female) were working in professional jobs, such as social work and occupational therapy but especially nursing roles, for 
example, 25 percent of all professional roles were undertaken by migrant women and 4 percent by migrant men.

\section{Sources of recruitment}

The NMDS-SC contained information on the source of recruitment relating to current main job for 50,128 men and 249,539 women. Our analysis shows that men were more likely to be recruited from outside the social care sector than from other social care employment. Men were also less likely to be recruited from retail and the health sector than women and were less likely to be 'returners' (going back to LTC after a break). Almost identical proportions of men and women had not been previously employed when they started their current jobs. The latter may suggest that men working in the care sector are not particularly doing so in response to periods of unemployment.

Figure 1 Percentage of men within different job roles (compared to the mean of men among all job groups (17.1\%)) NMDS-SC March 2011

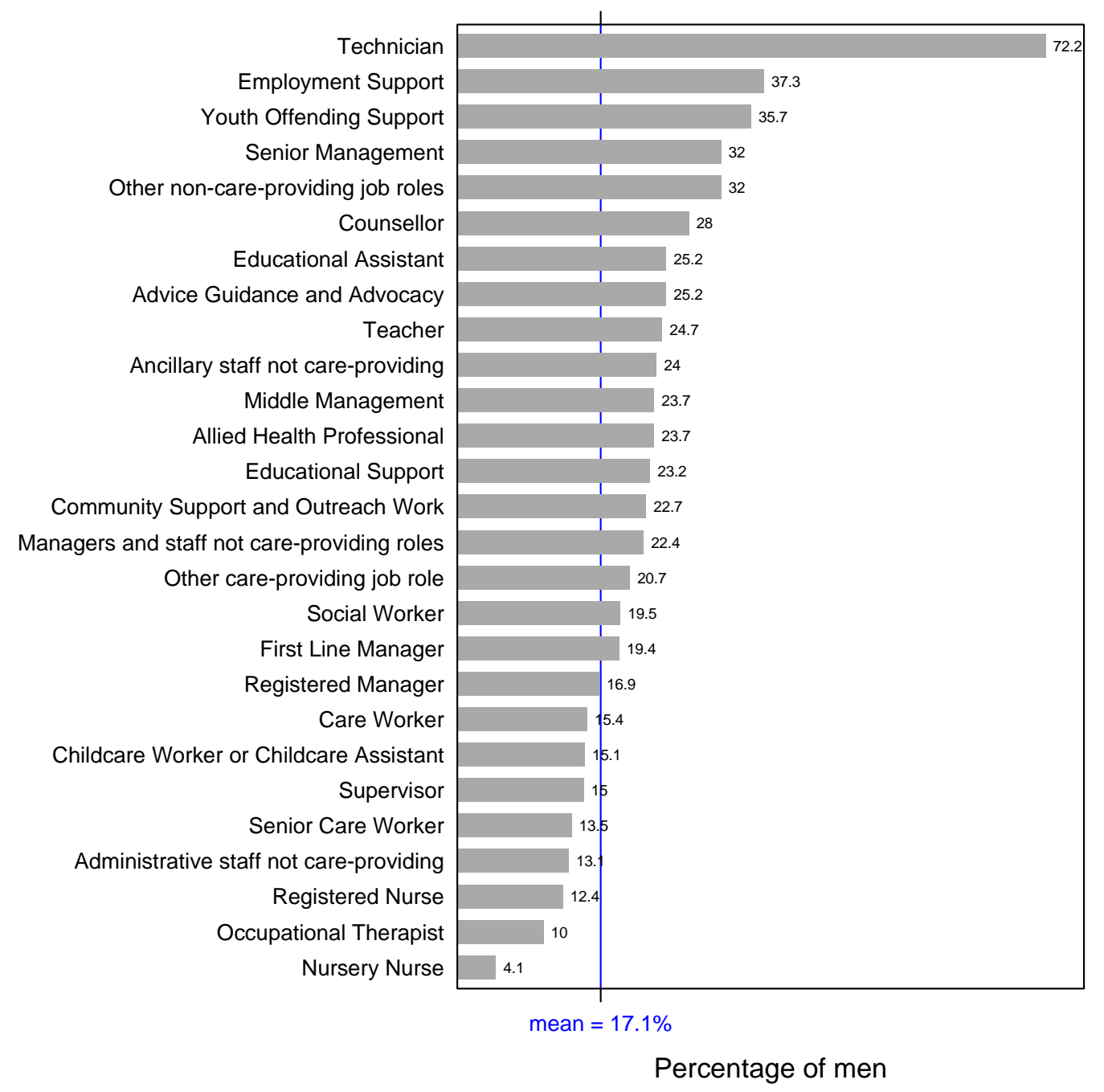




\section{LTC Organizational Characteristics and male recruitment}

Types of organizations, their management structure and local socio-economic characteristics seem likely to affect the acceptance and willingness of men to join the care sector and other predominantly female occupations. We explored the associations between different organizational characteristics of care providers and the prevalence of men within the LTC workforce. We started by exploring different patterns of associations then performed a mixed-effect model to examine and separate the effects of region, local (district level) authority (LA) and individual providers on the prevalence of men in this work. Similar to the distribution of the overall LTC workforce in England (SfC, 2012), the majority of men (59\%) in our sample worked in the private sector followed by the voluntary and LA sectors $(21 \%)$. Both men and women were similarly distributed across sectors. However, men were proportionally more likely to be employed within the voluntary sector than the private sector, and more men within the voluntary sector held managerial roles than within the private sector, while most professional men were employed by LAs.

Table 2 Distribution of social care workers by gender, sector and main service provision, NMDS-SC March 2011

\begin{tabular}{lcc} 
Organizational characteristics & Men & Women \\
\hline Sector & & \\
\hline Local Authority -LA (Adult) & $13.40 \%$ & $14.80 \%$ \\
LA (Children) & $1.40 \%$ & $1.30 \%$ \\
LA (Generic) & $0.30 \%$ & $0.30 \%$ \\
LA owned & $1.00 \%$ & $1.20 \%$ \\
Health & $0.20 \%$ & $0.10 \%$ \\
Private & $58.60 \%$ & $61.70 \%$ \\
Voluntary & $21.40 \%$ & $17.20 \%$ \\
Other & $3.70 \%$ & $3.40 \%$ \\
\hline Number of workers & 102,484 & 495,453 \\
\hline Main service provision & & \\
\hline Adult residential & $57.10 \%$ & $56.40 \%$ \\
Adult domiciliary & $28.30 \%$ & $34.10 \%$ \\
Adult community care & $8.40 \%$ & $5.80 \%$ \\
Adult Day Services & $4.00 \%$ & $2.70 \%$ \\
Children services & $2.20 \%$ & $1.00 \%$ \\
Health/Other services & $0.10 \%$ & $0.00 \%$ \\
\hline Number of workers & 93,717 & 462,825 \\
\hline
\end{tabular}

Table 2 shows that similar proportions of men and women worked in adult residential services (care homes), however, smaller proportions of men worked in domiciliary (home care services provided in users' own homes) services while more worked in community and day care services. Both men and women appeared to be working within organizations with similar turnover and vacancy rates. These findings suggest that men do not work in organizations where either vacancy or turnover rates are higher than average. 


\section{Levels of rurality and deprivation}

Bi-variate analysis showed men were significantly over-represented in social care employment in predominantly urban areas although local areas have different socioeconomic characteristics that are likely to affect labor participation by both men and women. Using the overall and sub-indices of the English Indices of Multiple Deprivation (IMD) 2007, Figure 2 indicated some positive relationships between the level of deprivation and prevalence of men in the sector, such association was observed with both income and employment sub-scales. These indicate that men were more prevalent in the LTC sector in more deprived areas.

Figure 2 Scatter plots of prevalence of men within the sector in different local areas by IMD 2007, its income and employment sub-scales, NMDS_SC March 2011 and IMD 2007†
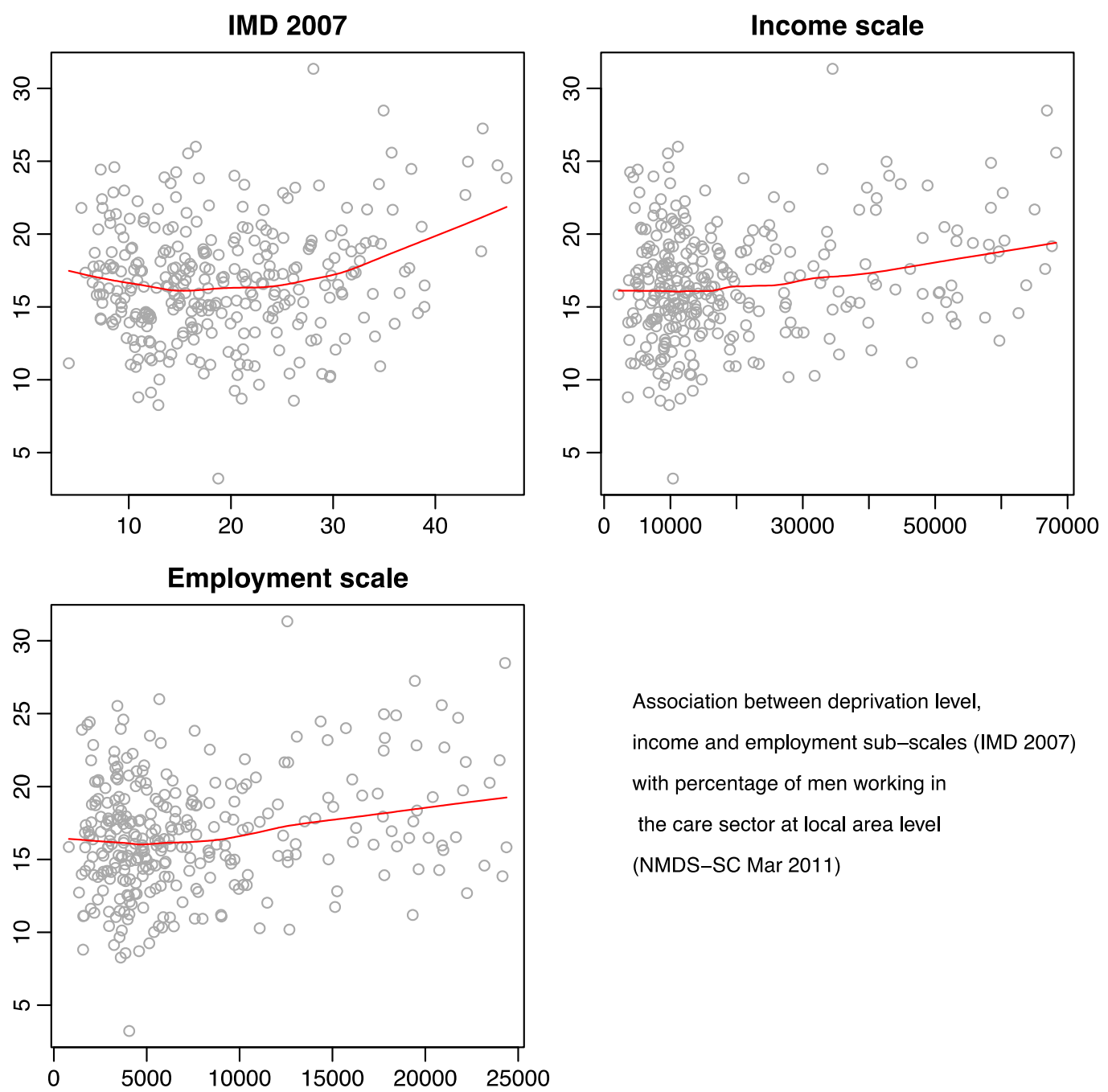

$\dagger$ The higher the deprivation scale the 'more deprived' the area; similarly the higher the income deprivation sub-scale the poorer the area and the higher the employment deprivation scale the higher unemployment rates 
Table 3 Results of fixed-effects of final mixed-effect model examining association between prevalence of men within organizations with different factors at three levels of hierarchy, NMDS-SC March 2011

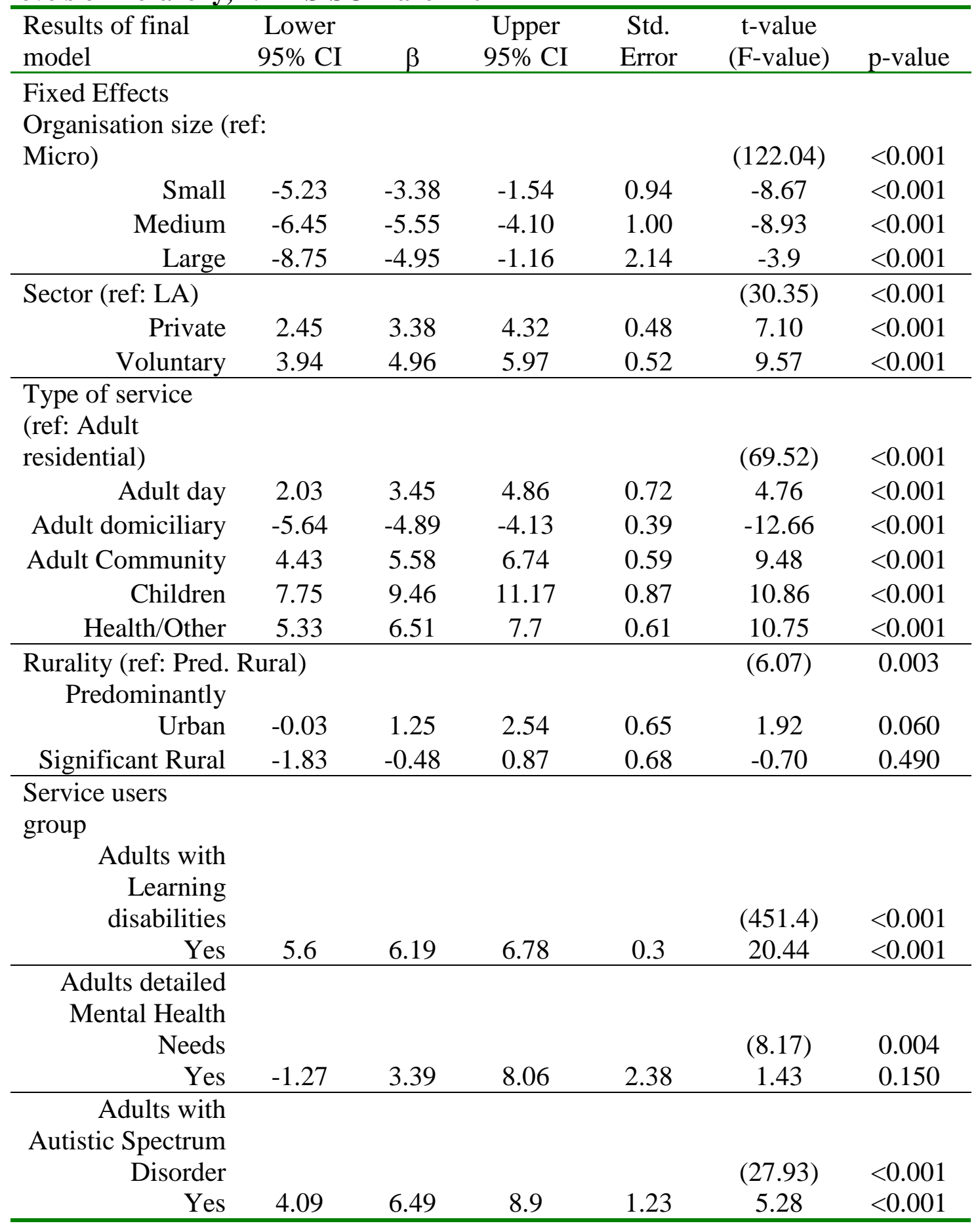

Using a mixed-effect model we examined the association and hierarchical effect of different factors on the prevalence of men within individual organizations. The model examined variations in the prevalence of men within a total of 19,369 organizations (complete cases) nested within 326 district councils (smaller than LAs) nested within nine geographical regions. Tables 3 and 4 present the results of the final model for the fixed and random effects. The final model indicated several variables were associated with the prevalence of men within different organizations. The vast majority of 
variance in the prevalence of men was attributable to organizational level (within organization variance) after controlling for the local council and region effects. Only two percent of the variance was attributable to the effect of local council while only one percent was attributable to the effect of the region (see Table 4).

The final model did not reveal any significant associations between local deprivation measures and prevalence of men within care organizations after controlling other variables; however, some of the variations were accounted for in the two percent attributed to unmeasured variance for local councils (as a random effect). Level of rurality was significantly associated with the prevalence of men in the workforce at the organizational level $(\mathrm{F}=6.07 ; \mathrm{p}=0.003)$.

At organizational level, several fixed effects, or measurable variables, were significantly associated with the prevalence of men within organizations providing LTC. Organization size, sector, type of service and certain main user groups were significantly associated with the presence of male workers. One of the factors showing the largest magnitude on the prevalence of men within the workforce was organizational size, with micro (small) organizations employing proportionally more men. Medium-sized organizations had the lowest prevalence compared to the mean within organizations $(19.54 \%)(\beta=-5.55 ; \mathrm{p}<0.001)$. Men were significantly more likely to be employed in the voluntary and the private sectors with 4 to 6 percent points above the mean $(\beta=5.97$ and 4.32 respectively; $p<0.001)$. The model shows that men were least likely to work in organizations providing domiciliary care $(\beta=-$ $4.89 ; \mathrm{p}<0.001)$. On the other hand, men were significantly more likely to work in organizations providing services to adults with learning disability (intellectual impairment $)(\beta=6.19 ; \mathrm{p}<0.001)$ and adults with autistic spectrum disorders $(\beta=6.49$; $\mathrm{p}<0.001)$.

Table 4 Results of random-effects of final mixed-effect model examining association between prevalence of men within organizations with different factors at three levels of hierarchy, NMDS-SC March 2011

\begin{tabular}{lccccc}
\hline Random effects & $\begin{array}{c}\text { Lower 95\% } \\
\text { conf }\end{array}$ & $\begin{array}{c}\text { Estimated } \\
\text { value }\end{array}$ & $\begin{array}{c}\text { Upper } \\
95 \%\end{array}$ & $\begin{array}{c}\text { Estimated } \\
\text { variance }\end{array}$ & $\begin{array}{c}\% \text { Overall } \\
\text { variance }\end{array}$ \\
\hline Region & 1.07 & 1.88 & 3.33 & 3.55 & $0.97 \%$ \\
Local council & 2.37 & 2.74 & 3.17 & 7.50 & $2.06 \%$ \\
Organisation & & & & & 353.59 \\
(Within group) & 18.62 & 18.80 & 18.99 & $96.97 \%$ \\
\hline Total variance & & & & 364.64 & \\
\hline
\end{tabular}

\section{Discussion and Conclusion}

With the expanding demand for long-term care,more attention is being given to attracting 'non-traditional' workers into the sector. Parallel to this, in the current UK economic climate, securing employment is becoming more difficult and sectors with an abundance of jobs, such as the LTC sector, may be in a good position to recruit those who may have not considered such jobs previously. However, workforce trends' analysis (Hussein, 2011b) shows that among the group of men working in LTC, proportionally more men had joined their current employment year on year since 
2000 (from $12.8 \%$ in 2000 to $19.1 \%$ in 2010); indicating slight increases in the proportion of men over time. This means that it would be mistaken to see any upward trend of male employment in the sector as entirely attributable to growing unemployment.

While these factors are acknowledged, at the heart of the nature and economics of care, care work remains a personal service not simply a product. At its core is the development of relationships and it is governed by interacting social and personal norms making the commodification of care far from a smooth market-led process. Yet, LTC as an employment sector is expanding and interacts with traditionally neighboring sectors, such as health and housing services, as well as associated sectors such as leisure, technology and employment support; offering greater opportunities for traditionally more-masculine jobs.

While globalization, labor market composition and the availability of jobs locally all play roles in attracting men to non-traditional work, issues related to societal acceptance, cultural and gendered norms and the secondary position of the sector may be presenting barriers to attracting male workers. Research interest in men who join female-dominated occupations is growing, but is still in its infancy. Most of such research relates to the advantages associated with such choices and may be regarded as building on Kanter's 'token' theory developed in the 1970s (Kanter, 1977). While migrant men and global care labor markets have commanded recent attention (for example: Kilkey, 2010; Hussein, 2011b) research largely concentrates on the nursing domain continuing the tradition inspired by colonial studies of this workforce (see Yeates, 2009).

The NMDS-SC provides a unique opportunity to investigate a very large sample of men working in the LTC sector in England. The analysis presented in this paper sought to develop an understanding of the profile, job roles and patterns of men within this sector and to investigate the characteristics of organizations that appear to attract more men than others.

Our findings highlight a number of important elements in relation to the contribution of men to the care sector. One of these findings relates to horizontal and vertical segregation among male workers. While the data indicate that around 17 percent the workforce are men, much higher percentages are observed in jobs that are traditionally masculine in nature, such as technicians, or managerial roles. There are similar observations from the nursing sector where care-tech boundaries are often related to gender (Lindsay, 2008), and may link to preserving masculine identity when joining a female-dominated occupation as suggested by Lupton (2000). This indicates that while some men appear to challenge occupational stereotypes by joining this female-dominated care sector, their choices or offers of specific jobs within the LTC sector are more 'masculine'. The over-representation of men in managerial roles may suggest the advantageous positions of men in the sector benefiting from their minority status applying the concept of 'glass escalator' (Williams, 1992). However, not all men seem to be in this position, migrant men are more concentrated within traditionally female jobs such as hands-on care work and less in managerial roles (Hussein, 2011b); highlighting the interaction between race and gender as presented in other domains (Kilkey, 2010). For migrant men such jobs can be the facilitator of 
the immigration act itself or just a part of their bigger 'life project' (Datta, 2009; Hussein et al, 2011; Hussein \& Christensen, forthcoming).

Employing a mixed-effect model to investigate factors affecting the prevalence of men in the organization level, we identified a significant role for the local area, particularly its level of rurality, with organizations in predominantly rural areas attracting more men. Men were significantly more likely to work in voluntary organizations, which may offer greater opportunities for career progression (Himmelweit \& Land, 2008) and therefore can be attractive initially and subsequently. They are also more likely to work for micro, or very small, businesses, possibly because of the different organizational structure these businesses may offer. Men are least prevalent in organizations providing LTC in users' own homes. The data also show that men are significantly more likely to be working in organizations providing care for certain user groups, possibly associated with traditional engagement with these groups that can be perceived to require male strength, role models and authority to 'manage' challenging behaviour (Mansell, Ashman, Macdonald \& Beadle-Brown, 2002).

Men in the sector appear to be recruited from a wider range of backgrounds than women, with larger percentages having other relevant qualifications and being recruited from outside the care and health sectors. Such findings chime with a smallscale qualitative study showing that men recruited to the sector usually 'stumble' upon such jobs (Vector Research, 2010), and are not necessarily building on previous work experience. These may also indicate men's greater scope for choice if they decide to join the LTC sector.

Given our findings related to the over-representation of men in job roles such as employment support, working with young adults, and advocacy there is potential for the sector to attract more men to these particular roles initially. The large number of men performing hands-on or direct care jobs suggest that many cross traditional boundaries, indicating that some, such as male migrants who are likely to be away from their habitual and societal constrains have the freedom to make such decisions or indeed may have limited alternatives. For migrant men, a different set of motivations might be in place including perceptions of what constitutes women and men's work in the first place (Solano \& Rafferty, 2006).

Our analyses establish that there are two sets of process in attracting men to the LTC sector; operating on the personal and organizational level. Recruitment strategies need to address both levels and report what works. Economic and labor market processes are clearly important, and affected by structure of job allocation by nationality and the significant influence of organizational type, local deprivation and level of rurality. Men were more present in this analysis, but not significantly so, in areas with higher deprivation scales (including lower incomes and higher unemployment levels), again indicating the influence of macro economic factors over personal individual choices. On the individual level, more men declared having a disability, which raises the question for researchers and others of whether this relates to higher levels of confidence to report this than women or indeed fewer work opportunities. These links between social class and participation in female-concentrated occupations have been indicated in qualitative research (Lupton, 2006) and some empirical research has 
supported possible relations between 'disadvantaged' men and their taking up of lower-status, female jobs (Marshall, Swift \& Roberts, 1997).

\section{Conclusion}

Using large national workforce data we were able to map the contribution of men to the LTC sector in England, highlighting several important elements. One of the main characteristics of such patterns relates to horizontal and vertical segregation of male workers, indicating important interactions between race/migration, socio-economic status, nationality and gender. The analyses further highlight the importance of organization characteristics, such as size, sector and type of work in attracting men and how local dynamics, such as rurality and local levels of unemployment and wealth, affect the involvement of men in LTC work. For researchers there are intriguing areas to explore further, such as the effectiveness of different recruitment strategies and length of stay in jobs and in the sector. This analysis reveals the potential of making more of large-scale data sets and suggests the value of national data collection systems that are able to be analysed and so identify possible significant comparisons and trends. For researchers such data may usefully complement other qualitative data and can highlight areas for further in depth investigation. In the English context, these areas include explorations of why men working in LTC are more likely to be found in smaller LTC provision and in the independent sector.

\section{Acknowledgements}

The authors thank SfC for providing the latest anonymous NMDS-SC data files. The views expressed in this report are those of the authors alone and should not necessarily be interpreted as those of the Department of Health or SfC.

\section{Funding}

This work is funded under the Department of Health Policy Research Programme support for the Social Care Workforce Research Unit at King's College London and by a National Institute for Health Research, Senior Investigator Award to Prof Jill Manthorpe, Grant number: NF-SI-0510- 10091.

\section{References}

Akaike, H. (1974) 'Information theory and an extension of the maximum likelihood principle.' in Second International Symposium on Information Theory. B. N. Petrov and F. Csáki (ed). Budapest: Akadémiai Kiado: 267-281.

Alksnis, C., Desmarais, S. and Curtis, J. (2008) Workforce Segregation and the Gender Wage Gap: Is "Women's" Work Valued as Highly as "Men's"? Journal of Applied Social Psychology, 38(6): 1416-1441.

Bagilhole, B. and Cross, S. (2006) 'It Never Struck Me as Female': Investigating Men's Entry into Female-dominated Occupations. Journal of Gender Studies, 15(1): 35-48.

Barnard, J. and Statham, D. (2012)The future adult social care workforce, Dartington, Research into Practice for Adults.

Bettio, F. and Vershchagina, A. (eds) (2002) Frontiers in the Economics of Gender, Routledge, New York: 243-265. 
Cameron, C. \& Moss, P. (1998) Men as carers for children: an introduction, in: C. Owen, C. Cameron \& P. Moss (Eds) Men as Workers in Services for Young Children: Issues of a Mixed Gender Workforce, London: Institute of Education.

Cross, S. and Bagilhole, B. (2002) "Girls" jobs for the boys? Men, masculinities and non-traditional work. Gender, Work and Organization, 9 (2): 204-226.

Christie, A. (1998) Is Social Work a 'Non-Traditional' Occupation for Men? British Journal of Social Work, 28(4): 491-510.

Davey, B. (2002) Management Progression and Ambition: Women and Men in Social Work. Research Policy and Panning, 20(2): 21-34.

Ellison, M., Russinova, Z., MacDonald-Wilson, K. and Lyass, A. (2003) Patterns and correlates of workplace disclosure among professionals and managers with psychiatric conditions Journal of Vocational Rehabilitation, 18(1): 3-13.

England, P., Allison, P. and Wu, Y. (2007) Does Bad Pay Cause Occupations to Feminize, Does Feminization Reduce Pay, and How Can We Tell with Longitudinal Data? Social Science Research 36: 1237-1256.

Evans, J. (1997) Men in nursing: issues of gender segregation and hidden advantage. Journal of Advanced Nursing 26: 226-231.

Furness, S. (2012) Gender at Work: Characteristics of 'Failing' Social Work Students. British Journal of Social Work, 42(3): 480-99.

Geerts, J. (2011) The long-term care workforce: description and perspectives,

European Network of Economic Policy Research Institutes. ENEPRI Research Report No. 93, August 2011,

http://www.cardi.ie/userfiles/Long\%20term\%20care\%20workforce(1).pdf

Hakim, C. (1996) Key Issues in Women's Work, London: Athlone Press.

Himmelweit, S. and Land, H. (2008) Reducing gender inequalities to create a sustainable care system, York, Joseph Rowntree Foundation.

Hussein S. (2011a) Migrant workers in long term care: evidence from England on trends, pay and profile. Social Care Workforce Periodical, Issue 12- March (accessed 9/9/13) http://www.kcl.ac.uk/sspp/kpi/scwru/pubs/periodical/issues/scwp12.pdf Hussein S. (2011b) In the minority: migrant men employed in female-dominated long-term care jobs in England. Paper presentation, Social Policy Association annual conference, Lincoln, $5^{\text {th }}$ July 2011.

Hussein, S. and Christensen, K. (forthcoming) Migrant men in women's work: on male migratory journeys crossing feminized elder care occupations.

Hussein, S., Moriarty, J. and Manthorpe, J. (2009) Variations in Progression of Social Work Students in England: Using Student Data to Help Promote Achievement: Under- graduate Full-Time Students' Progression on the Social Work Degree, London, Social Care Workforce Research Unit, King's College London

Hussein, S., Manthorpe, J. and Stevens M. (2011) Social care as first work experience in England: a secondary analysis of the profile of a national sample of migrant workers. Health and Social Care in the Community, 9(1): 83-97.

Jacobs, J. (1993) Men in female-dominated fields: trends and turnovers, in: C. L. Williams (Ed.) Doing Women's Work: Men in Non-traditional Occupations London: Sage.

Kanter, R. (1977) Men and women of the corporation. Boston: Harvard University Press.

Kilkey, M. (2010) Men and domestic labor: A missing link in the global care chain. Men and Masculinities, 13(1): 126-149.

Lindsay, S. (2008) The care-tech link: An examination of gender, care and technical work in healthcare labour, Gender, Work and Organisation, 15(4): 333-351. 
Loughrey, M. (2008) Just how male are male nurses? Journal of Clinical Nursing, 17: 1327-1334.

Lupton, B. (2000) Maintaining masculinity, men who do 'women's work'. British Journal of Management, 11, Special issue, S33-S48.

Lupton, B. (2006) Explaining men's entry into female-concentrated occupations: issues of masculinity and social class, Gender, Work and Organization 13: 103-128.

Lynch, K. (2007) Love labour as a distinct and non-commodifiable form of care labour. Sociological Review, 55: 550-570.

McLean, J. (2003) Men as Minority: Men Employed in Statutory Social Care Work. Journal of Social Work, 3(1): 45-68.

Mansell, J., Ashman, B., Macdonald, S. and Beadle-Brown, J. (2002) Residential care in the community for adults with intellectual disability: needs, characteristics and services, Journal of Intellectual Disability Research, 46 (8): 625-33.

Pease, B. (2011) Men in Social Work: Challenging or Reproducing an Unequal Gender Regime? Affilia, 26: 406-418.

Simpson, R. (2004) Masculinity at work: The Experiences of men in female dominated occupations, Work, Employment and Society, 18(2), pp. 349-68.

Skills for Care [SfC] (2012) The state of the adult social care sector and workforce in England, October 2012. Leeds: Skills for Care.

Solari, C. (2006) Professionals and saints: How immigrant careworkers negotiate gender identities at work. Gender \& Society 20: 301-331.

Solano, D. and Rafferty, A. M. (2006) Can lessons be learned from history? The origins of the British imperial nurse labour market: a discussion paper. International Journal of Nursing Studies, 44 (2007): 1055-1063.

Twigg, J. (2000) Bathing - the body and community care, London: Routledge.

Vector Research (2009) Improving the recruitment of men into the care sector in the West Midlands. Birmingham: Final report to Skills for Care West Midlands.

Williams, C. (1992) The glass escalator: Hidden advantages for men in female professions. Social Problems 39: 253-267.

Williams, L.S. and Villemez, W.J. (1993) Seekers and finders: male entry and exit in female dominated jobs. In Williams, C.L. (ed.) Doing 'Women's Work': Men in Nontraditional Occupations, pp. 64-90. Sage: London.

Wingfield, A. (2009) Razializing the glass escalator. Reconsidering men's experiences with women's work. Gender \& Society, 23: 5-26.

Yeates, N. (2009) Globalizing Care Economies and Migrant Workers: Explorations

in Global Care Chains, Palgrave Macmillan: New York.

\section{NOTES}

iThe NMDS-SC is the first attempt to gather standardized workforce information for the social care sector. It is developed, run and supported by Skills for Care and aims to gather a 'minimum' set of information about services and staff across all service user groups and sectors within the social care sector in England. The NMDS-SC was launched in October 2005 and the online version in July 2007 and since then there has been a remarkable increase in the number of employers completing the national dataset.

ii For details of data item collected by NMDS-SC see: http://www.nmds-sconline.org.uk/content/view.aspx?id=NMDS-SC\%20data\%20items

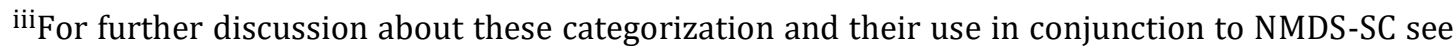
(Hussein 2011). For more information on MDI 2007 see Nobel et al (2008). For further information on urban/rural categorization see:www.ons.gov.uk; these are three-way 
classifications of 'Predominantly Rural' (R50 and R80), 'Significant Rural' (SR) or 'Predominantly Urban' (OU, MU and LU) are obtained for each CSSR.

iv Model improvements were tested using AIC (Akaike Information Criteria) and BIC (Bayesian information criteria) to select the best model (Akaike, 1974).

'Skills for Care introduced a new field of 'don't know' from June 2011 to reflect when employers are not sure about their workers' nationalities. The data set used in the analyses presented here is prior to such additions.

viGrouped as: 1. 'Managers/supervisors': senior management, middle management, first line manager, registered manager, supervisor, managers and staff in care-related jobs; 2. 'Direct care': senior care worker, care worker, community support, employment support, advice and advocacy, educational support, technician, other jobs directly involving care; 3. 'Professional': social workers, occupational therapists, registered nurse, allied health professional, qualified teacher; 4. 'Other': administrative staff, ancillary staff, and other job roles not directly involving care.

\section{Notes on contributors}

Shereen Hussein, BSc, MSc, PhD is a demographer with a broad interest in sociology and economics. Her research interests include migration and care; wages and occupation inequalities; and relationships between organisational structure, stress and quality of care work.

Mohamed Ismail, MEng, MComp, MSc, is the Director of Analytical Research Ltd. an independent research organisation specialised in quantitative modelling and research for the public and private sectors. He has extensive experience in quantitative methodologies and their applications in the financial sector and social science.

Jill Manthorpe is Professor of Social Work at King's College London and Director of the Social Care Workforce Research Unit. She is also Associate Director of the NIHR School for Social Care Research and her main research interests lie in care and older people, particularly around risk, dementia and social care practice. 